\title{
RST analysis of MSG-SEVIRI TIR radiances at the time of the Abruzzo 6 April 2009 earthquake
}

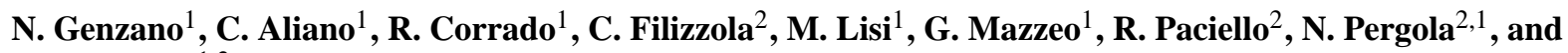 \\ V. Tramutoli ${ }^{1,2}$ \\ ${ }^{1}$ University of Basilicata, Department of Engineering and Physics of the Environment, Potenza, Italy \\ ${ }^{2}$ National Research Council, Institute of Methodologies for Environmental Analysis (IMAA), Tito Scalo (PZ), Italy
}

Received: 31 October 2009 - Accepted: 10 November 2009 - Published: 11 December 2009

\begin{abstract}
Space-time fluctuations of Earth's emitted Thermal Infrared (TIR) radiation have been observed from satellite months to weeks before earthquakes occurrence.

The general RST approach has been proposed in order to discriminate normal (i.e. related to the change of natural factor and/or observation conditions) TIR signal fluctuations from anomalous signal transient possibly associated to earthquake occurrence. In this work RST approach is applied to the Abruzzo 6 April 2009 event $\left(M_{L}=5.8\right)$ by using for the first time MSG-SEVIRI (Meteosat Second Generation -Spinning Enhanced Visible and Infrared Imager) thermal infrared observations. A validation/confutation analysis has been performed in order to verify the presence/absence of anomalous space-time TIR transients in the presence/absence of significant seismic activity. MarchApril 2009 has been analyzed for validation purposes. Relatively unperturbed periods (no earthquakes with $M_{L} \geq 5$ ) have been taken for confutation. A specific TIR anomalies spacetime persistence analysis as well as a cloud coverage distribution test have been introduced in order to eliminate artifacts and outliers both in the validation and confutation phases. Preliminary results show clear differences in TIR anomalies occurrence during the periods used for validation and confutation purposes. Quite clear TIR anomalies appear also to mark main tectonic lines related to the preparatory phases of others, low magnitude $\left(M_{L} \sim 4\right)$ earthquakes, occurred in the area.
\end{abstract}

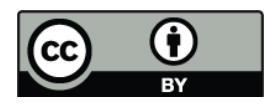

Correspondence to: N. Genzano (nicogenzano@gmail.com)

\section{Introduction}

Several studies (see for example Gorny et al., 1988; Qiang and Dian, 1992; Tronin, 1996; Qiang et al., 1997; Tronin et al., 2002; Ouzounov and Freund, 2004) have been performed, in the past years, reporting the appearance of spacetime anomalies in TIR satellite imagery, from weeks to days, before severe earthquakes. Different authors (Qiang et al., 1991; Tramutoli et al., 2001, 2009), in order to explain the appearance of anomalously high TIR records near the place and the time of earthquake occurrence, attributed their appearance to the increase of green-house gas (such as $\mathrm{CO}_{2}$, $\mathrm{CH}_{4}$, etc.) emission rates, to the modification of ground water regime (see Hamza, 2001) and/or to the increase of convective heat flux (Qiang et al., 1991; Tronin, 2000; Surkov et al., 2006). Other, more complex models (e.g. Mareev et al., 2002; Pulinets et al., 2002, 2006, 2007; Molchanov, 2004; Molchanov et al., 2004; Ouzounov and Freund, 2004; Tronin et al., 2004; Molchanov and Hayakawa, 2008) have been proposed, that include the increase of near surface temperature, among the other expected pre-seismic phenomena.

Nevertheless such a claimed correlation has been considered, up to now, with some caution by scientific community. The main problems of the mentioned studies were the lack of a rigorous definition of anomalous TIR signal fluctuations, the absence of a convincing testing step based on a validation/confutation approach and the scarce attention paid to the possibility that other causes (e.g. meteorological) different from seismic activity could be responsible for the observed TIR variations.

Considering what has been said, a different approach named Robust Satellite data analysis Technique (RST; Tramutoli, 2007), based on the RAT - Robust AVHRR

Published by Copernicus Publications on behalf of the European Geosciences Union. 
(Advanced Very High Resolution Radiometer) Techniques - approach (Tramutoli, 1998), was proposed to investigate possible relations between earthquake occurrence and spacetime fluctuations of Earth's emitted TIR radiation as observed from satellite. The RST analysis is mainly based on:

- a statistically based definition of "TIR anomalies" allowing their identification even in very variable local (e.g. related to atmosphere and/or surface) and observational (e.g. related to time/season, but also to solar and satellite zenithal angles) conditions,

- a validation/confutation approach, devoted to verify the presence/absence of anomalous space-time TIR transients in the presence/absence of seismic activity.

The RST approach was already tested in the case of tens of earthquakes (Tramutoli et al., 2001b, 2005, 2009; Di Bello et al., 2004; Filizzola at al., 2004; Corrado et al., 2005; Genzano et al., 2007, 2009; Aliano et al., 2007, 2008a, b, c) occurred in different continents (Europe, Asia, America and Africa), in various geo-tectonic settings (compressive, extensional and transcurrent) and with a wide range of magnitudes (from 4.0 to 7.9).

In this paper, the results of RST analysis performed on 5 years of MSG-SEVIRI TIR data collected over the Italian peninsula are presented.

Results achieved at the time of Abruzzo earthquake (6 April 2009, $M_{L} \sim 5.8$ ) are compared with an identical analysis (confutation) performed in a quite unperturbed (characterized by the absence of earthquakes of similar magnitude over the same area) year, in order to verify the presence/absence of anomalous space-time TIR transients in the presence/absence of significant earthquakes in similar observational conditions.

\section{A robust estimator of thermal anomalies}

The RST approach (Tramutoli, 2007) based on the RAT approach (Tramutoli, 1998), is a suitable tool for monitoring different natural and environmental risks. RST has been successfully applied to the major natural and environmental hazards related to: volcano activity (Pergola et al., 2001, 2004a, b; Tramutoli et al., 2001c; Di Bello et al., 2004; Bonfiglio et al., 2005; Marchese et al., 2006; Filizzola et al., 2007); flood risk (Tramutoli et al., 2001a; Lacava et al., 2005, 2006, 2009); forest fires (Cuomo et al., 2001; Mazzeo et al., 2007), etc.

RST was applied for the first time to seismically active areas monitoring, in the case of the disastrous 1980 Irpinia-Basilicata earthquake (Di Bello et al., 2004; Tramutoli et al., 2001b), then it was successfully tested in several cases: Athens, 7 September 1999 (Filizzola et al., 2004); Izmit, 17 August 1999 (Tramutoli et al., 2005); Gujarat, 26 January 2001 (Genzano et al., 2007), Boumerdes/Thenia,
21 May 2003 (Aliano et al., 2007); Hector Mine, 16 October 1999 (Aliano et al., 2008a), Umbria-Marche, October 1997 (Aliano et al., 2008b), Mestia Tianeti (Georgia), 23 October 1992 (Genzano et al., 2009), and various low magnitude events occurred in Greece and Turkey, May and June 19951996 (Corrado et al., 2005).

The RST approach has been always implemented by using a validation/confutation approach, in order to verify the presence/absence of anomalous space-time TIR transients in the presence/absence of significant seismic events. The RST technique is based on a preliminary multi-temporal analysis on several years (at least five, better more) of homogeneous historical data-set of satellite TIR records, which is devoted to characterize the TIR signal (in terms of its expected value and variation range) for each pixel of the satellite image to be processed. On this basis, anomalous TIR patterns are identified by using a specific index, RETIRA (Robust Estimator of TIR Anomalies, Filizzola et al., 2004; Tramutoli, 2005), to be computed on the image at hand as:

$\otimes_{\Delta T}(\boldsymbol{r}, t)=\frac{\Delta T(\boldsymbol{r}, t)-\mu_{\Delta T}(\boldsymbol{r})}{\sigma_{\Delta T}(\boldsymbol{r})}$

where:

$\boldsymbol{r} \equiv(x, y)$ represents location coordinates of the pixel centre on a satellite image; $t$ is the time of image acquisition with $t \in \tau$, where $\tau$ defines the homogeneous domain of satellite imagery collected in the same time-slot of the day and period (month) of the year;

$\Delta T(\boldsymbol{r}, t)=T(\boldsymbol{r}, t)-T(t)$ is the value of the difference between the punctual value of brightness temperature $T(\boldsymbol{r}, t)$ at the location $\boldsymbol{r} \equiv(x, y)$ and acquisition time $t$, and its spatial average $T(t)$ computed on the investigated area considering only cloud-free locations, all belonging to the same, land or sea, class (i.e. considering only sea pixels if $\boldsymbol{r}$ is located on the sea and only land pixels if it is located on the land). Note that the choice of such a differential variable $\Delta T(\boldsymbol{r}, t)$ instead of $T(\boldsymbol{r}, t)$ is expected to reduce possible contributions (e.g. occasional warming) due to day-to-day and/or year-toyear climatological changes and/or season time-drifts;

$\mu_{\Delta T}(\boldsymbol{r})$ time average value of $\Delta T(\boldsymbol{r}, t)$ at the location $\boldsymbol{r} \equiv(x, y)$ computed on cloud free records belonging to the selected data set $(t \in \tau)$;

$\sigma_{\Delta T}(\boldsymbol{r})$ standard deviation of $\Delta T(\boldsymbol{r}, t)$ at the location $\boldsymbol{r} \equiv(x, y)$ computed on cloud free records belonging to the selected data set $(t \in \tau)$.

In this way $\otimes_{\Delta T}(\boldsymbol{r}, t)$ gives the local excess of the current $\Delta T(\boldsymbol{r}, t)$ signal compared with its historical mean value and weighted by its historical variability at the considered location. Both, $\mu_{\Delta T}(\boldsymbol{r})$ and $\sigma_{\Delta T}(\boldsymbol{r})$, are computed, once and for all, for each location $\boldsymbol{r}$, processing several years of historical satellite records acquired in similar observational conditions. They are two reference images describing the normal behaviour of the signal and of its variability at each location $\boldsymbol{r}$ in observational conditions as similar as possible to the ones of the image at hand. Excess $\Delta T(\boldsymbol{r}, t)-\mu_{\Delta T}(\boldsymbol{r})$ 


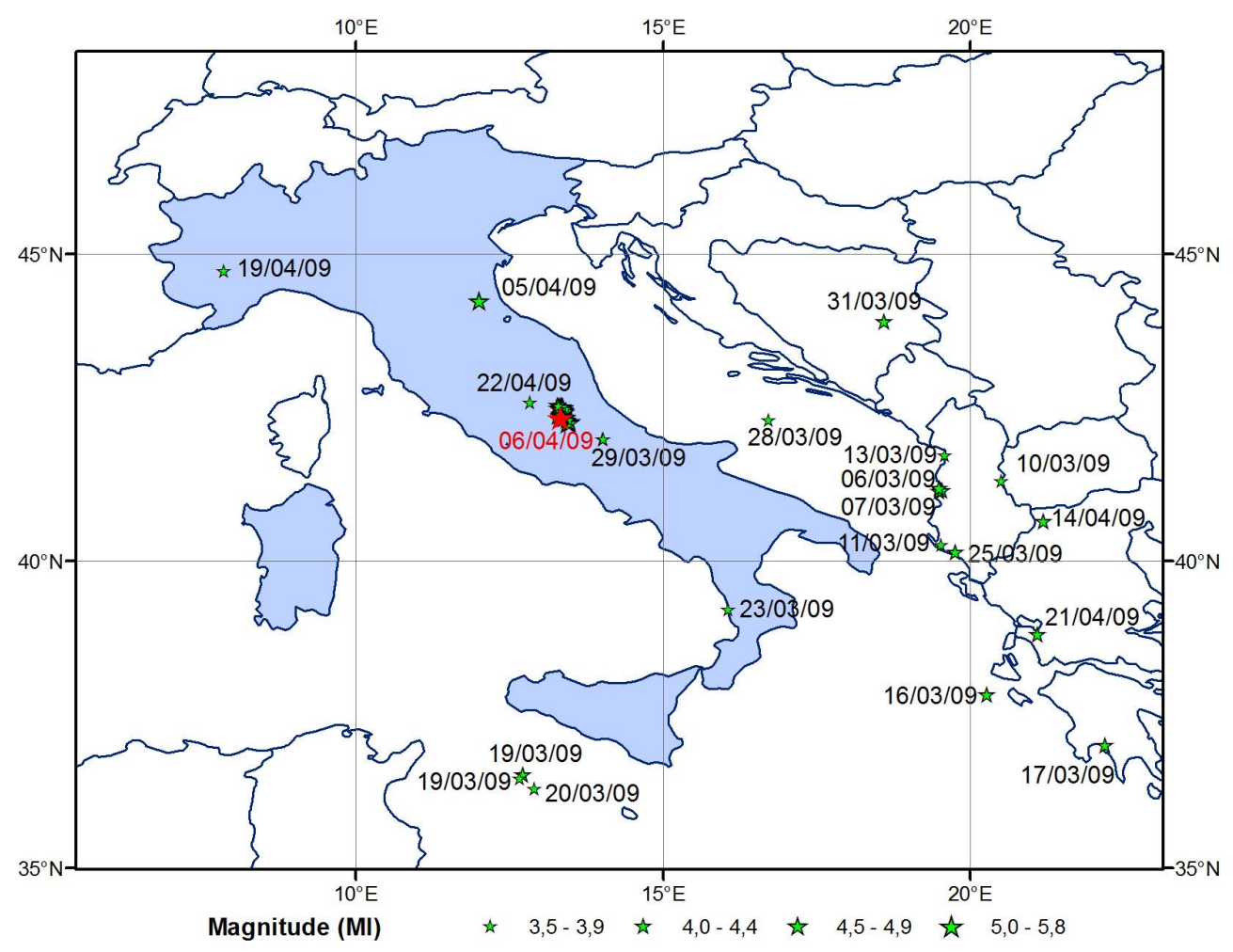

Fig. 1. Seismic events with $M_{L}>3.5$ occurred in March and April 2009. Red star indicates the main shock of Abruzzo earthquakes (INGV, 2009).

then represents the Signal (S) to be investigated for its possible relation with seismic activity. It is always evaluated by comparison with the corresponding natural/observational Noise $(\mathrm{N})$, represented by $\sigma_{\Delta T}(\boldsymbol{r})$ which describes the overall (local) variability of $\mathrm{S}$ including all (natural and observational, known and unknown) sources of its variability as historically observed at the same site in similar observational conditions (sensor, time of day, month, etc). This way, the relative importance of the measured TIR signal (or the intensity of anomalous TIR transients) can naturally be evaluated in terms of $\mathrm{S} / \mathrm{N}$ ratio by the RETIRA index.

A wider description of the RST approach and its implementation on different satellite sensors to monitor seismic areas can be found in Tramutoli et al. (2005), Aliano et al. (2008a) and in the other above mentioned papers.

\section{The case of Abruzzo earthquake}

The Abruzzo earthquake $\left(M_{L} \sim 5.8\right)$ occurred on 6 April 2009 at 01:32:39 GMT, having its epicentre at $42.334^{\circ} \mathrm{N}$ and $13.334^{\circ} \mathrm{E}$ (INGV 2009). The mainshock occurred as a result of normal faulting on a NW-SE oriented structure in the central Apennines. The same zone has been object of frequent seismic events (Fig. 1) with characteristics of seismic swarm beginning from January 2009, with hundreds of shakes all of modest entity. The seismicity was confined in the upper crust interesting an area about $30 \mathrm{~km}$ long and strikes in the NWSE direction, parallel to the Apennine mountain axis and to the main fault structures known in the area.

In this paper, the Abruzzo seismic event has been analyzed using the RST approach applied to MSG-SEVIRI data. Five years of TIR satellite imagery acquired from 2005 to 2009 in the same time of the day (24:00 GMT) during the months of March and April were used for computing $\mu_{\Delta T}(\boldsymbol{r})$ and $\sigma_{\Delta T}(\boldsymbol{r})$ reference fields shown in Fig. 2 .

On this basis RETIRA index has been computed for all the MSG-SEVIRI imagery in order to perform the validation/confutation analysis. For validation purposes, the months of March and April 2009 have been considered, while, in the confutation phase, the analysis has been performed considering the months of March and April 2008: the "unperturbed" (i.e. no earthquakes with $M \geq 5$, in the same region and in the same months but in a different year) period in the considered data set.

Reference fields (time average $\mu_{\Delta T}(\boldsymbol{r})$ and standard deviation $\sigma_{\Delta T}(\boldsymbol{r})$ ) for the investigated area for March and April computed from SEVIRI data collected at 24:00 UTC during the years 2005-2009. 


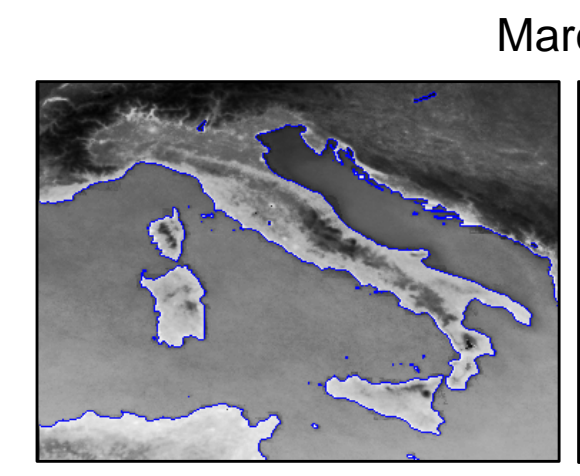

March
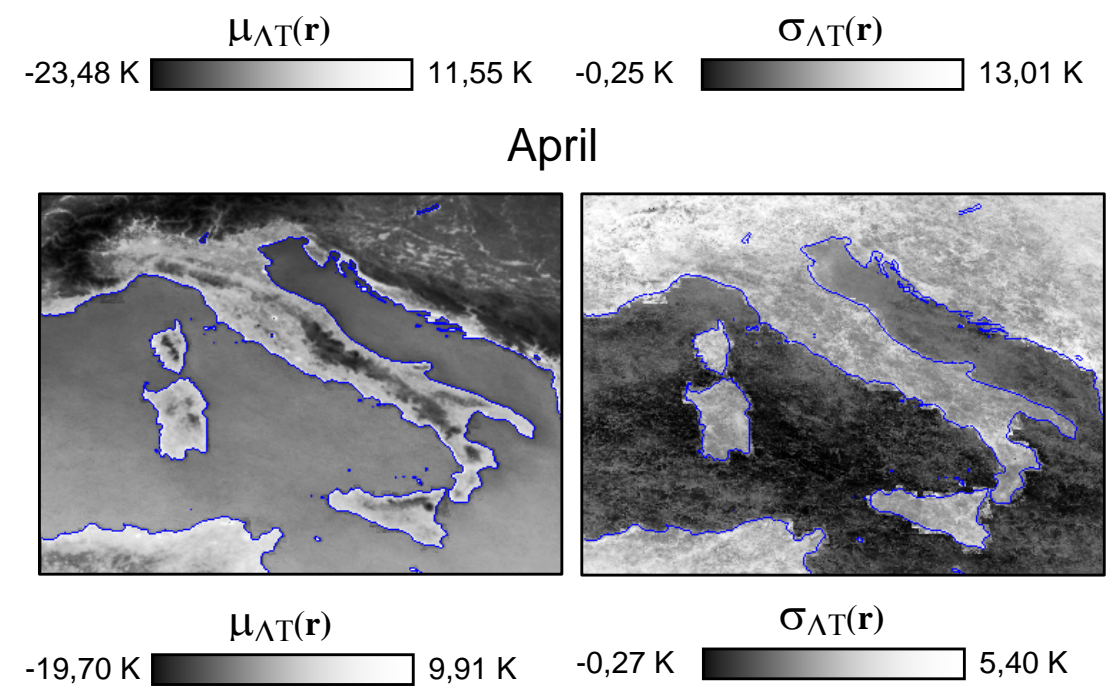

Fig. 2. Reference fields (time average $\mu_{\Delta T}(\boldsymbol{r})$ and standard deviation $\sigma_{\Delta T}(\boldsymbol{r})$ ) for the investigated area for March and April computed from SEVIRI data collected at 24:00 UTC during the years 2005-2009.

\section{Validation}

The validation phase has been performed for the period 15 March-15 April 2009. Scenes affected by a wide cloudy coverage ( $>80 \%$ of the total scene, e.g. 29 March 2009 in Fig. 3) are not shown as well as images affected by artifacts due to the computation of RETIRA index on few cloudsfree pixels (one example in Fig. 3, more details on the socalled cold spatial average effect can be found are in Aliano et al., 2008a). The results of RETIRA index computation are shown in Fig. 4, where pixels with $\otimes_{\Delta T}(\boldsymbol{r}, t) \geq 4$ (i.e. with the signal excess $\left.\Delta T(\boldsymbol{r}, t)-\mu_{\Delta T}(\boldsymbol{r})>4 \sigma_{\Delta T}(\boldsymbol{r})\right)$ are depicted in red (hereafter, only for the sake of simplicity, we will refer to them simply as "TIR anomalies"). Pixels affected by clouds (which completely mask Earth's emitted radiation in the TIR spectral region) have been detected by using OCA (One-channel Cloudy-radiance-detection Approach, Cuomo et al., 2004) and excluded from whatever further processing and analysis.

Looking at the sequence of pictures in Fig. 4 it is possible to note that higher intensity anomalies $\left(\otimes_{\Delta T}(\boldsymbol{r}, t) \geq 4\right)$ appear in the Italian peninsula affecting the north of Italy at 16 and 24 March in the Piedmont region and on 28 March in the Padania plain, while the central Italy (the Abruzzo region) and the Calabria coast are affected by TIR anomalies beginning from 30 March until 1 April. Other higher intensity anomalies appear in the Balkan region on 21 March near the Croatia coast and on 30 and 31 March, and 4 April in the Bosnia region, while on 28 March TIR anomalies are also visible in the North Africa.

As already discussed in previous works (Filizzola et al., 2004; Tramutoli et al., 2005; Aliano et al., 2008a), the RETIRA index is intrinsically not protected from the abrupt occurrence of signal outliers related to particular natural (e.g. local warming due to night-time cloud passages) or observational (e.g. errors in image navigation/co-location process) conditions.

For this reason TIR anomalies sequences have been subjected to a space-time persistence analysis in order to discriminate actually significant anomalous space-time transients from outliers. This is, for instance, the case of thermal anomalies which appear in Northern Africa on 28 March: 


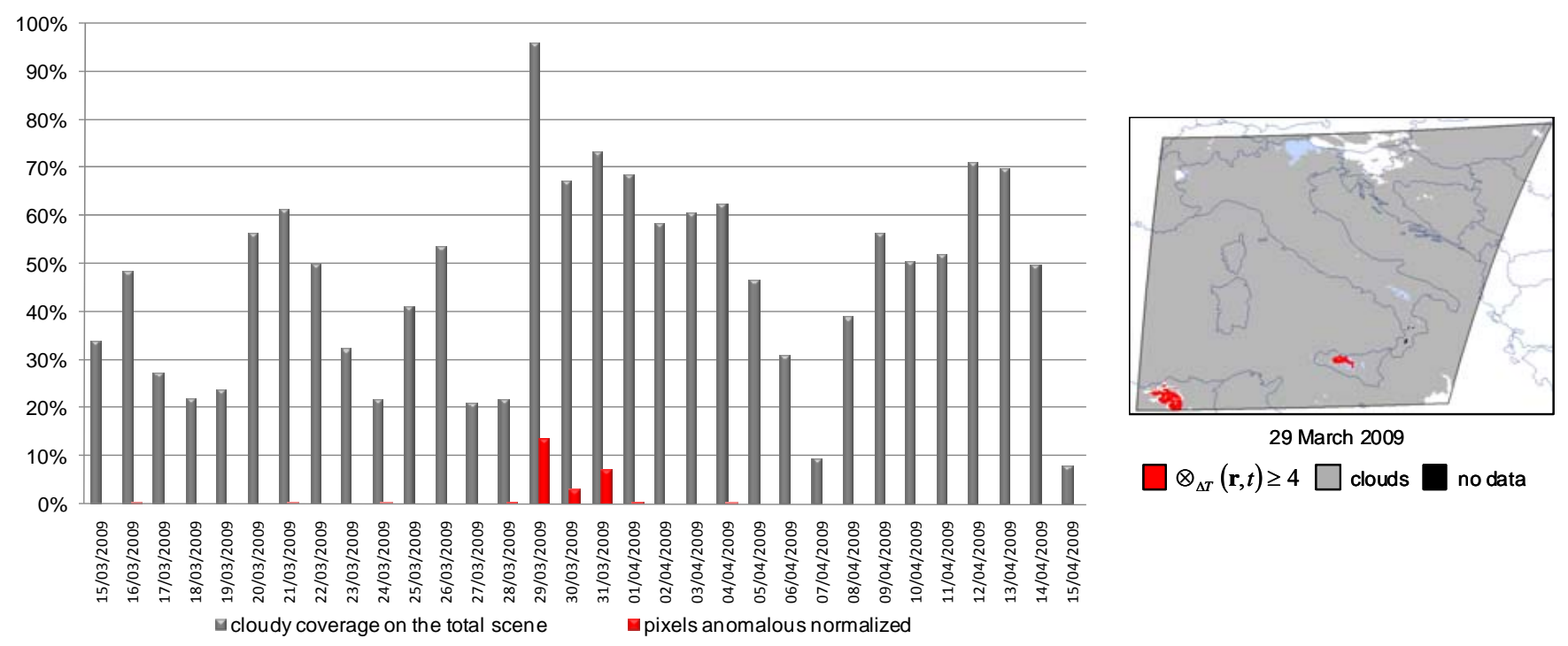

Fig. 3. Left side: calculation of cloudy coverage over all the SEVIRI scenes processed for the 2009: grey bars represent the percentage of cloudy pixels over the total number of pixels in the image; red bars represent the percentage of TIR anomalies (RETIRA $\geq 4$ ) over the remaining cloud free pixels in the image. Right side: example, on the 29 March 2009 scene, of artefacts (spurious TIR anomalies) due to the poorness of cloud-free pixels where RETIRA index can be computed and to the clouds masking quite all the warmest part of the scene (cold spatial average effect, see text).

a local warming effect due to the night time passage of a cloudy system has been identified as the probable responsible for this spatially extended but not time persistent anomaly. Spatial extension and persistence in time are in fact the further requirements to be satisfied (together with relative intensity) in order to preliminarily identify significant TIR anomalies.

If we consider lower intensity TIR anomalies (pixels with $\left.\otimes_{\Delta T}(\boldsymbol{r}, t) \geq 3\right)$ it is possible to better appreciate the time evolution of the TIR anomalies before observed. Generally, low intensity anomalies follow the ones of higher intensity noticeably enlarging the anomaly area and filling gaps both in the space (among isolated anomalous pixels) and time domains.

On the basis of these considerations and looking at Fig. 1 where seismic events with $M_{L}>3.5$ occurred in the period March-April 2009 are shown, it is possible to distinguish between pre- and post-seismic thermal anomalies. Among the TIR pre-seismic anomalies it is possible to discern 3 main sequences:

- TIR anomalies are visible in the central area of Italy from 30 March to 1 April (5 days before the mainshock of Abruzzo earthquake) located near the main tectonic lineaments and the seismic epicentres of the earthquakes occurred in the Abruzzo area (Fig. 5a);

- TIR anomalies at different levels of intensity are present in the north of Italy (Piedmont region) beginning from 16 March until 28 March. They affect this area in cor- respondence with a tectonic lineament showing a variable persistence in the space and time domain (Fig. 5b). A seismic event (Bra earthquakes) with magnitude $M_{L} \sim 3.9$ occurred in this area on 19 April 2009;

- also in the Padana plain since 31 March until 3 April lower intensity TIR anomalies are present with a variable spatial distribution near the tectonic lineament (Fig. 5c). The regions has been affected by an earthquake (Forli earthquakes) on 5 April $2009\left(M_{L} \sim 4.6\right)$.

On the Balkan area it is possible to appreciate pre- and postseismic anomalies (Fig. 6). TIR anomalies occurred in this area, with a variable spatial distribution and different levels of intensity, from 30 March (1 day before an earthquake with magnitude $M_{L}=4.2$ occurred in the same area) until 4 April.

\section{Confutation}

The confutation step has been performed by considering the same period (15 March-15 April) but in a different year (2008), in order to verify the absence of TIR anomalies in a relatively seismically unperturbed period. The selection of 2008 for confutation purposes has been done consulting the INGV (2009) seismic catalogue within the range 2005-2009 (years for which MSG-SEVIRI data were available): no seismic events with magnitude greater than (or equal to) 5 are reported over the investigated area during the months of March and April 2008 (Fig. 7a). 


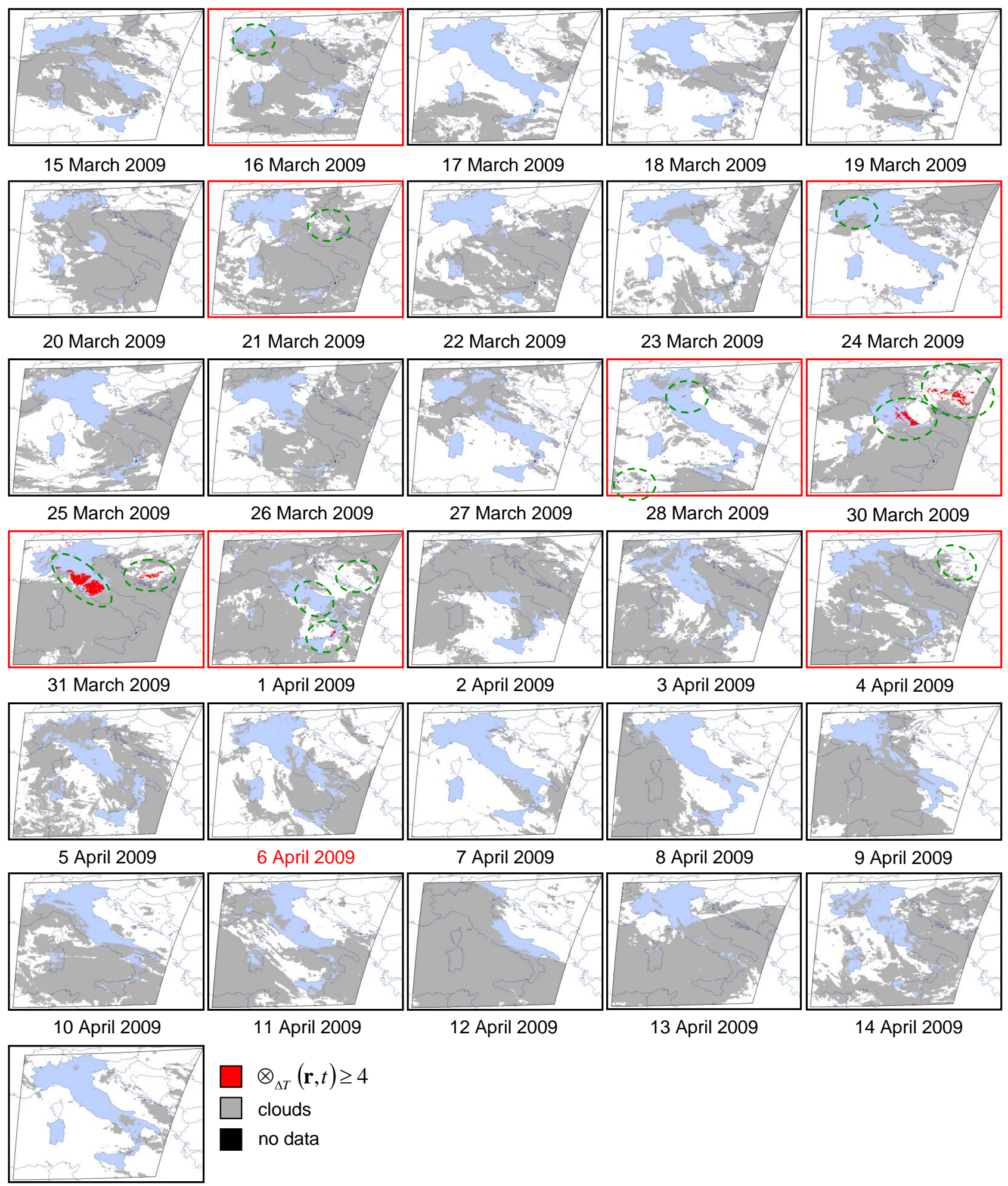

15 April 2009

Fig. 4. Validation: results of the RETIRA index computation on the investigated area before and after the Abruzzo earthquake (6 April 2009, $M_{L} \sim 5.8$ ). All scene from 15 March and 15 April are shown with the exclusion of those scenes (in this case only the one acquired on 29 March) affected by clouds covering more than $80 \%$ of the whole scene. Thermal anomalies (i.e. pixels with $\left.\otimes_{\Delta T}(\boldsymbol{r}, t) \geq 4\right)$ are depicted in red. Cloudy locations are depicted in gray. Red boxes contour images containing TIR anomalies. Green dashed circle indicate the areas of occurrence of TIR anomalies (see test). 


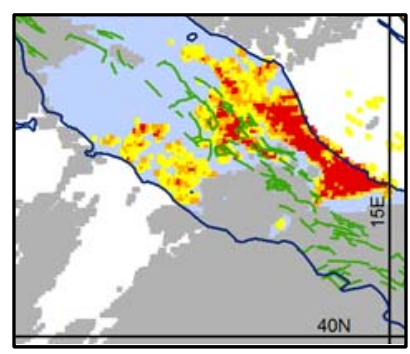

(a)

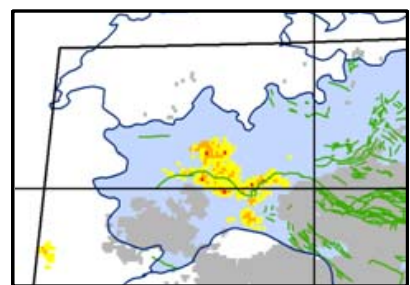

16 March 2009

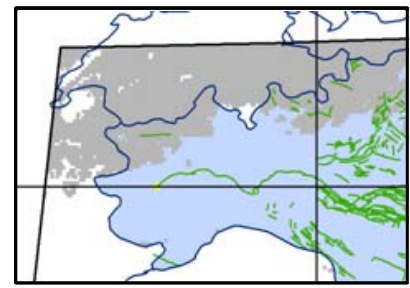

26 March 2009

(b)

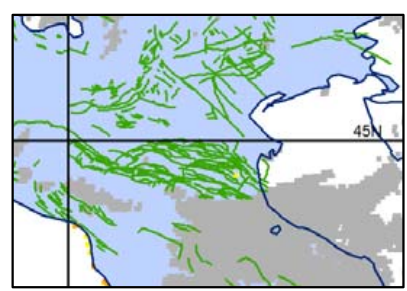

21 March 2009

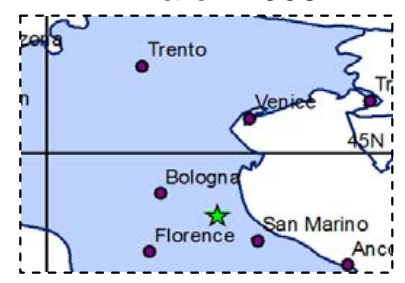

Forlì earthquakes epicenter

(c)

$5^{\text {th }}$ April 2009 (Ml 4.6)

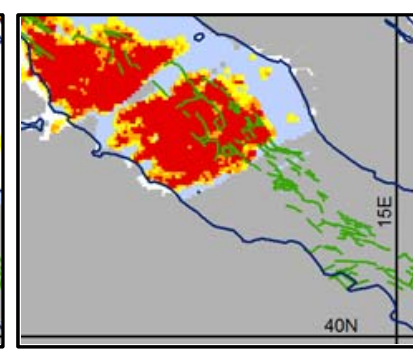

31 March 2009

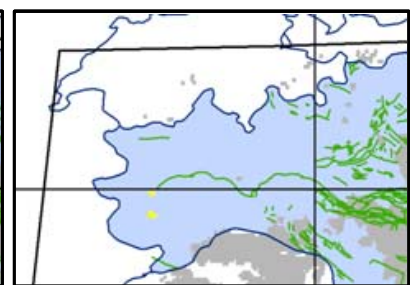

19 March 2009

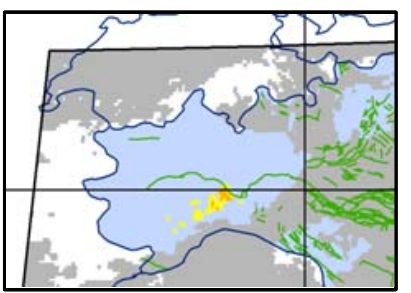

27 March 2009

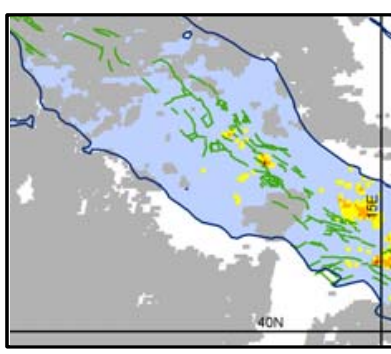

1 April 2009

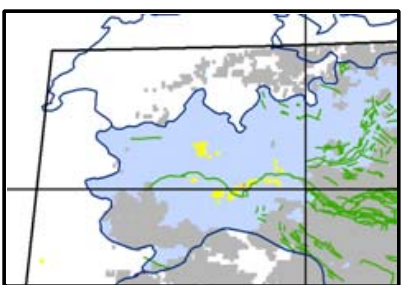

20 March 2009

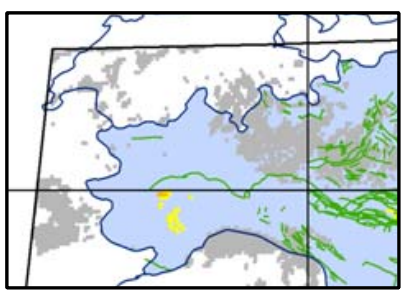

28 March 2009

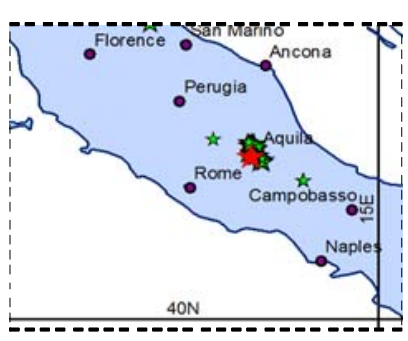

Abruzzo seismic events

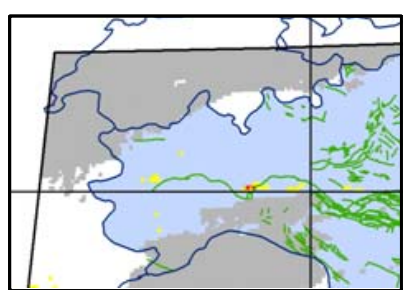

24 March 2009

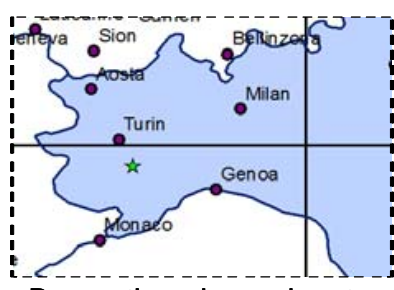

Bra earthquakes epicenter

$19^{\text {th }}$ April $2009(\mathrm{Ml} 3,9)$

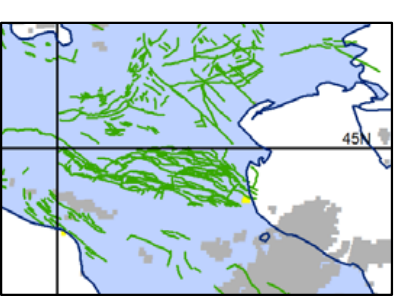

22 March 2009

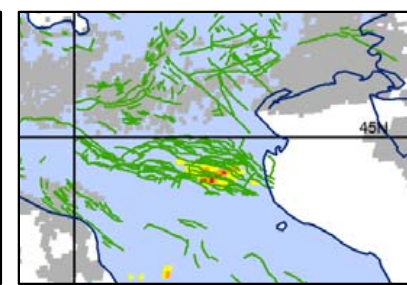

28 March 2009

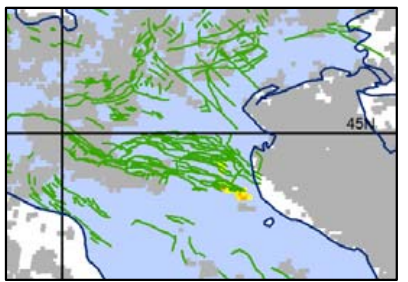

3 April 2009

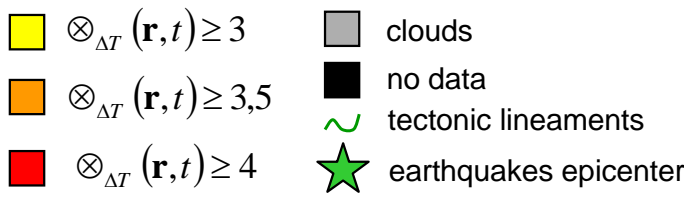

$\square \otimes_{\Delta T}(\mathbf{r}, t) \geq 4 \quad \widetilde{W}$ earthquakes epicenter

Fig. 5. Validation: pre-seismic anomalies, a close view in different region: (a) Abruzzo region, (b) Piedmont region, and (c) Padana plain. Seismic events information come from INGV (2009). 


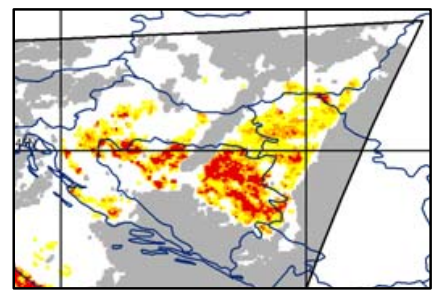

30 March 2009

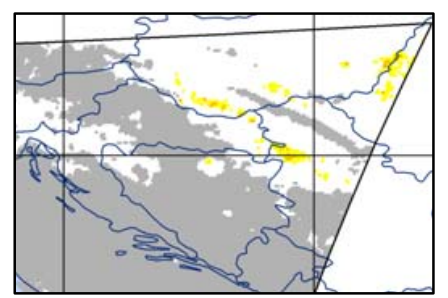

3 April 2009

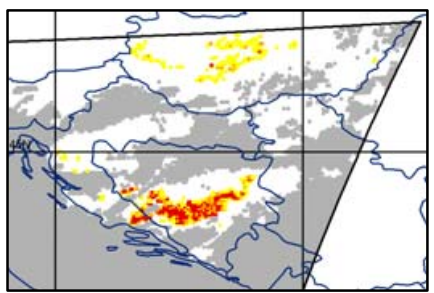

31 March 2009

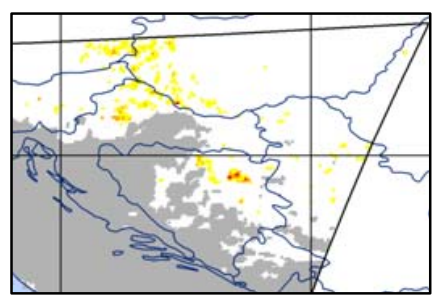

4 April 2009

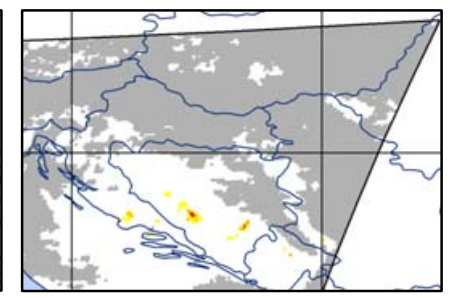

1 April 2009

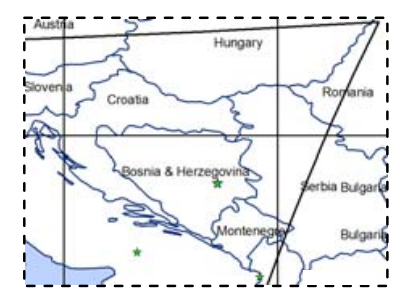

Bosnia earthquakes epicenter $31^{\text {st }}$ March 2009 (MI 4,2)

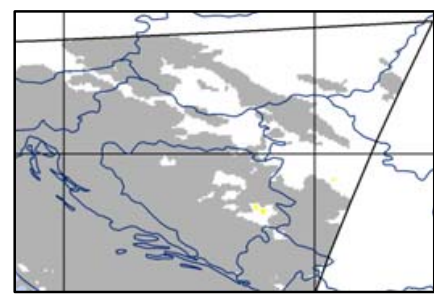

2 April 2009

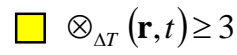

$\square \otimes_{\Delta T}(\mathbf{r}, t) \geq 3,5$

$\square \otimes_{\Delta T}(\mathbf{r}, t) \geq 4$

$\square$ clouds

no data

饮 earthquakes epicenter

Fig. 6. Validation: pre- and post-seismic anomalies; a close view in the Balkan region.

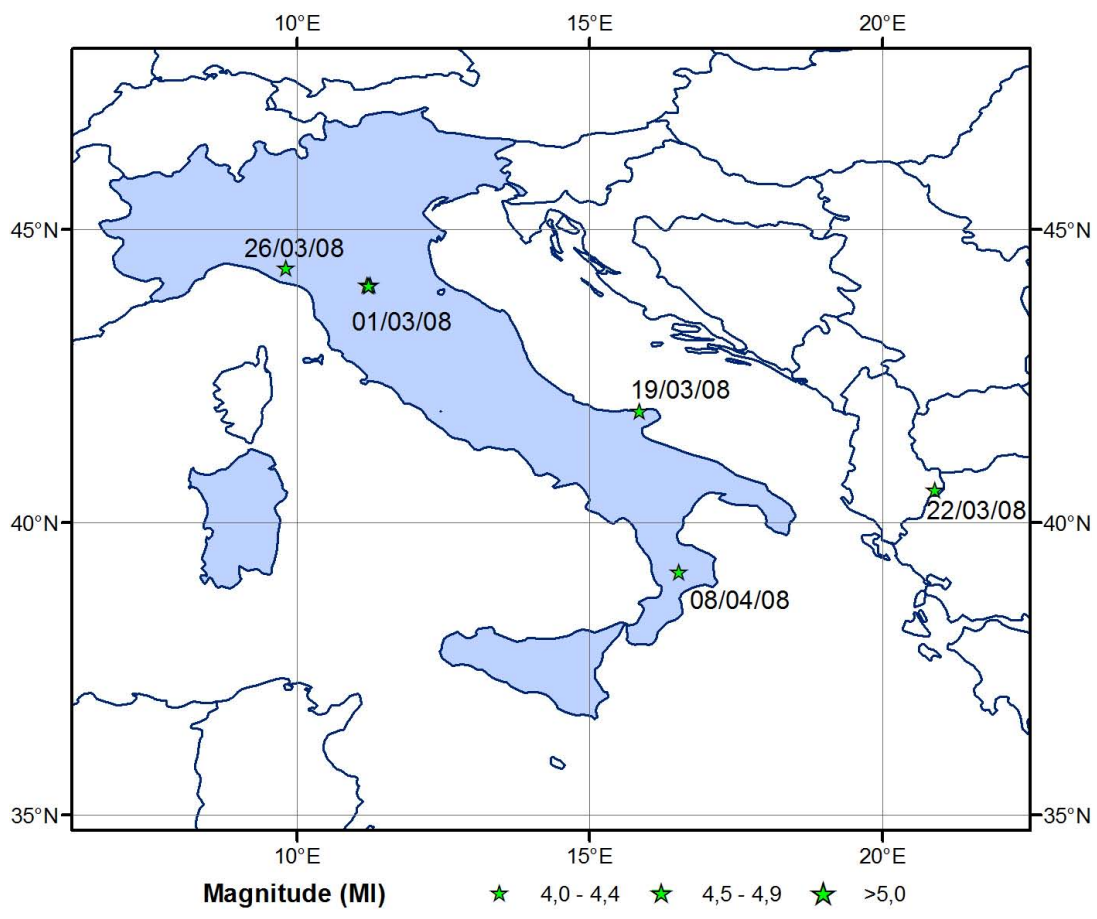

Fig. 7a. Seismic events $\left(M_{L} \geq 4\right)$ occurred during March-April 2008 (INGV, 2009).

As for the validation step, the same cut at $4 \sigma$ (i.e. $\left.\otimes_{\Delta T}(\boldsymbol{r}, t) \geq 4\right)$ has been used in order to identify images containing TIR anomalies. Scenes (8, 10, and 11 April) affected by a wide ( $>80 \%$ ) cloudy coverage have been excluded from the analysis (Fig. 7b).

Figure 8 shows the result of the RST analysis for the 2008. It is possible to note that only from 16 March until 20 March space-time persistent TIR anomalies appear which affect Southern Italy (Calabria region) reaching their maximum extension on 19 March. A seismic event with magnitude $M_{L} \sim 4.0$ occurred in the same area on 8 April 2008. In the following days only spatially isolated and/or not time persistent TIR anomalies appears (disappearing just in one day) probably related to night-time cloud passages (e.g. $24 \mathrm{March}$ 2008). 


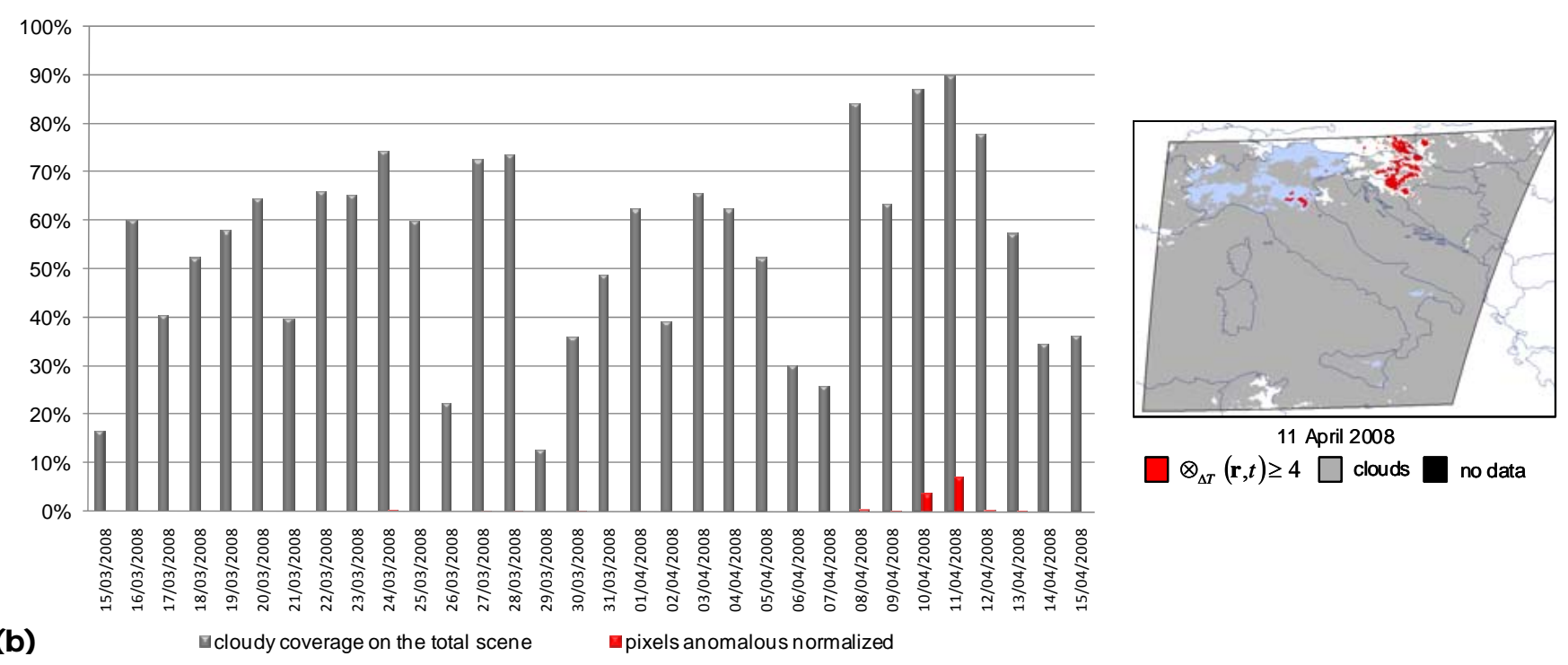

Fig. 7b. Left: calculation of cloudy coverage on all the scenes processed for 2008: grey bars represent the percentage of cloudy pixels over image; red bars represent the percentage of anomalous pixels over the remaining cloud free pixels in the image; Right: example on the 11 April 2008 scene of artefacts (spurious TIR anomalies) due to the poorness of cloud-free pixels where RETIRA index can be computed and to the cloud masking all the warmest part of the scene (cold spatial average effect, see text).

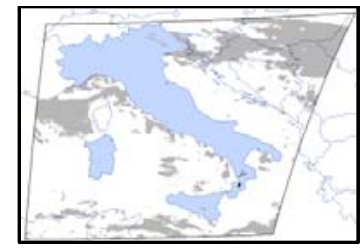

15 March 2008

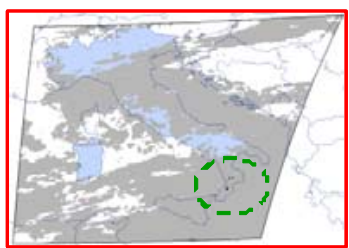

20 March 2008

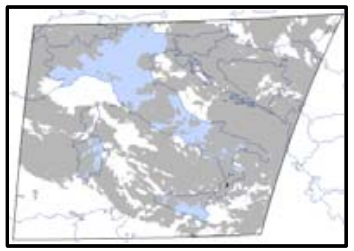

25 March 2008

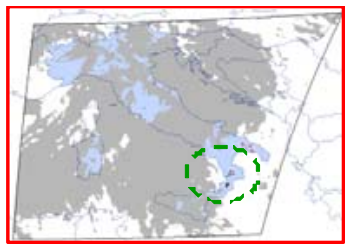

16 March 2008

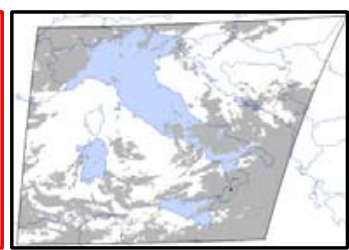

21 March 2008

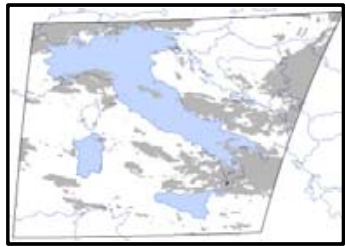

26 March 2008

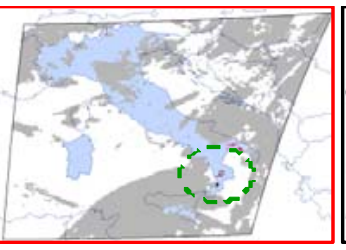

17 March 2008

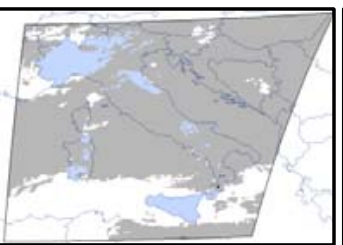

22 March 2008

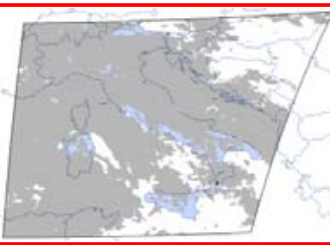

27 March 2008

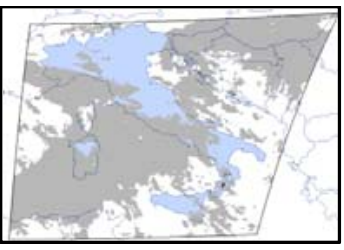

18 March 2008

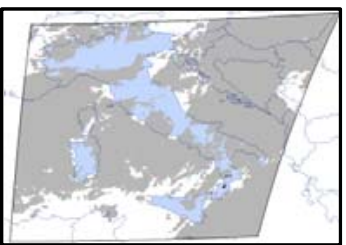

23 March 2008

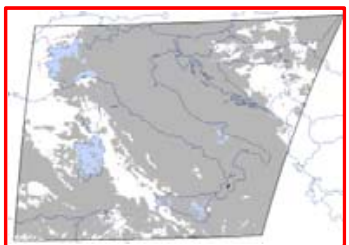

28 March 2008

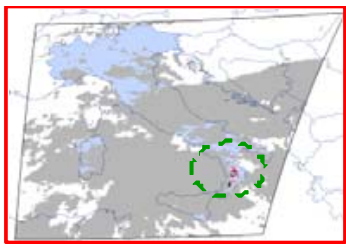

19 March 2008

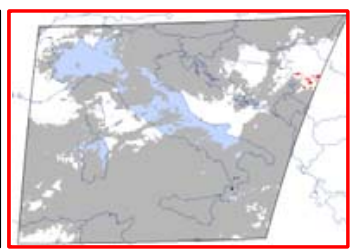

24 March 2008

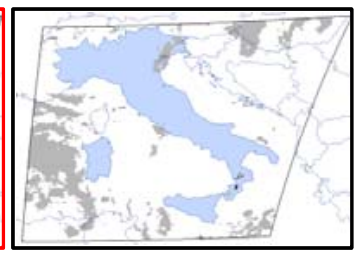

29 March 2008

Fig. 8. Confutation: results of the RETIRA index computation over the investigated area for the relatively unperturbed year 2008. Red boxes contour images having pixels with $\otimes_{\Delta T}(\boldsymbol{r}, t) \geq 4$. Green circle indicate the (unique) sequence of space-time persistent TIR anomalies over Calabria region. 


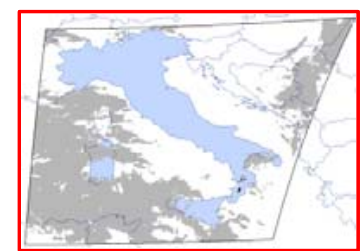

30 March 2008

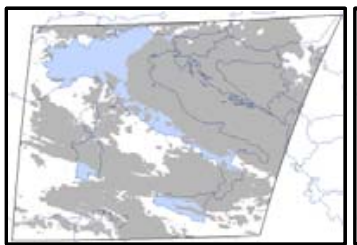

4 April 2008

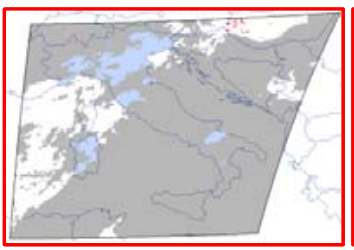

12 April 2008

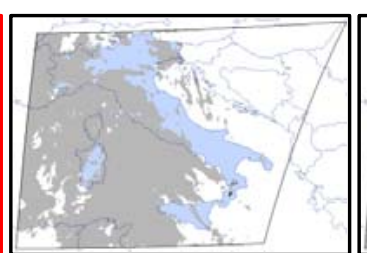

31 March 2008

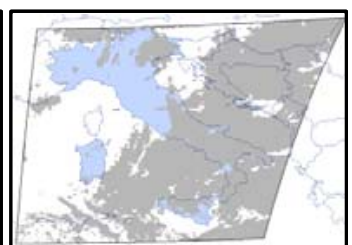

5 April 2008

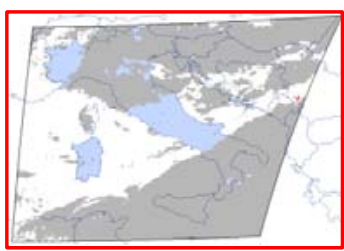

13 April 2008

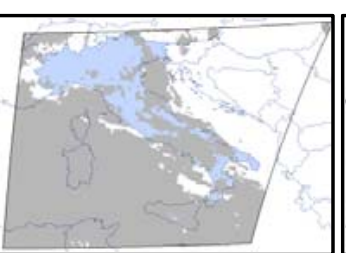

1 April 2008

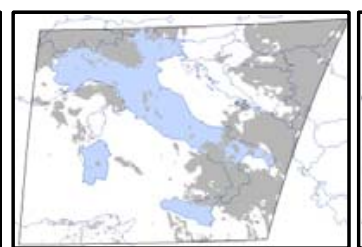

6 April 2008

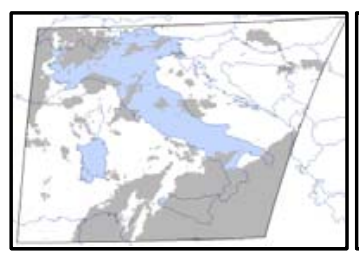

14 April 2008

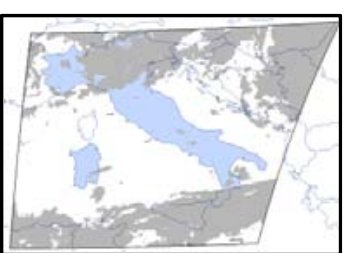

2 April 2008

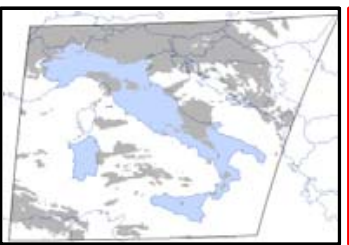

7 April 2008

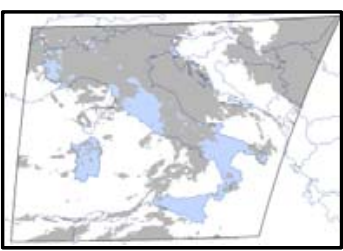

15 April 2008

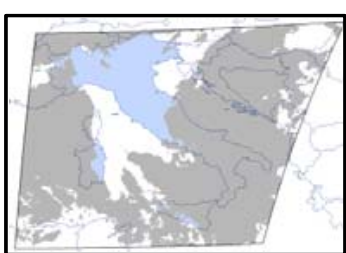

3 April 2008

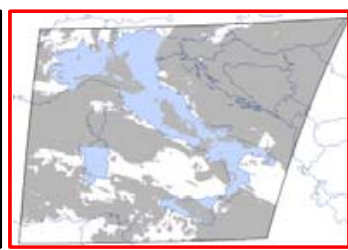

9 April 2008

$\square \otimes_{\Delta T}(\mathbf{r}, t) \geq 4$

clouds

no data

Fig. 8. Continued.

\section{Conclusions}

In this paper, the RST analysis has been applied for the first time to thermal image acquired by SEVIRI sensor on board MSG satellites, in order to verify the possible space-time relationships among TIR anomalies appearance and seismic events occurrence. The Abruzzo earthquake (6 April 2009, $M_{L} \sim 5.8$ ) has been considered as a test case for validation, while a relatively unperturbed period (no earthquakes with $M \geq 5$ ) was taken for confutation in the same months (MarchApril) of a different year (2008).

The validation/confutation approach puts in relief that thermal anomalies with RETIRA $>4$ (the highest relative intensity and $\mathrm{S} / \mathrm{N}$ observed until now) appear in the central part of Italy five days before the main shock of Abruzzo earthquake (6 April 2009, $M_{L} \sim 5.8$ ). No similar anomalies have been observed in the absence of earthquakes in similar observation conditions in the period (March-April 2008) considered for confutation.

The possible relation between TIR anomalies appearance and medium-low magnitude earthquake, already documented by previous work (e.g. Corrado et al., 2005) is confirmed, in fact TIR anomalies persistent in the space-time domain have been observed in Italy from few days to few weeks before seismic events of medium-low magnitude (Calabria, 8 April 2008, $M_{L} \sim 4.0$; Forlì, 5 April 2009, $M_{L} \sim 4.6$; Bra, 19 April 2009, $M_{L} \sim 3.9$;) and in the Balkan region both before and after an earthquake of $M_{L}=4.2$ here occurred on 31 March 2009.
An original approach to identify and exclude TIR anomalies purely due to the effect (already described in Aliano et al., 2008a) of cloud cover and spatial distribution was proposed. Nevertheless the presence of clouds continue to limit the possibility to well investigate space-time persistence of TIR anomalies.

The use of passive MicroWave (MW) sensors could help to overcome such limitations. In fact, this kind of electromagnetic radiation, by penetrating (not raining) clouds, allows us to observe Earth's surface in any weather conditions. Even if passive MW sensors operate with a spatial resolution $(10-50 \mathrm{~km}$ nadir view), which is much lower than the one $(1-5 \mathrm{~km})$ achievable by TIR sensors, such spatial resolution remains largely sufficient to monitor thermal anomalies we observed always at a wider scale around the epicentre zone.

Acknowledgements. The authors wish to thank the Aeronautica Militare Italiana for its support to have access to MSG-SEVIRI data used in this work.

Edited by: P. F. Biagi

Reviewed by: two anonymous referees

\section{References}

Aliano, C., Corrado, R., Filizzola, C., Pergola, N., and Tramutoli, V.: Robust Satellite Techniques (RST) For Seismically Active Areas Monitoring: The Case Of 21st May, 2003 Boumerdes/Thenia (Algeria) Earthquake, in: Proceedings of 
Multitemp 2007, 1-6, doi:10.1109/MULTITEMP.2007.4293042, available at: http://ieeexplore.ieee.org/xpl/tocresult.jsp?isnumber= 4293029\& is Year=2007, 2007.

Aliano, C., Corrado, R., Filizzola, C., Genzano, N., Pergola, N., and Tramutoli V.: TIR Satellite Techniques for monitoring Earthquake active regions: limits, main achievements and perspectives, Ann. Geofis., 51(1), 303-317, 2008a.

Aliano, C., Corrado, R., Filizzola, C., Pergola, N., and Tramutoli, V.: Robust satellite techniques (RST) for the thermal monitoring of earthquake prone areas: the case of Umbria-Marche October, 1997 seismic events, Ann. Geofis., 51(2/3), 451-459, 2008b.

Aliano, C., Corrado, R., Filizzola, C., Genzano, N., Lanorte, V., Lisi, M., Martinelli, G., Pergola, N., and Tramutoli, V.: Robust Satellite Techniques for monitoring TIR anomalies in seismogenic areas, in: Proceedings of the Second Workshop on the Use of Remote Sensing Techniques for Monitoring Volcanoes and Seismogenic Areas, doi:10.1109/USEREST.2008.4740365, 2008c.

Bonfiglio, A., Macchiato, M., Pergola., N., Pietrapertosa, C., and Tramutoli, V.: AVHRR automated detection of volcanic clouds, Int. J. Remote Sens., 26(1), 9-27, 2005.

Corrado, R., Caputo, R., Filizzola, C., Pergola, N., Pietrapertosa, C., and Tramutoli, V.: Seismically active area monitoring by robust TIR satellite techniques: a sensitivity analysis on low magnitude earthquakes in Greece and Turkey, Nat. Hazards Earth Syst. Sci., 5, 101-108, 2005, http://www.nat-hazards-earth-syst-sci.net/5/101/2005/.

Cuomo, V., Lasaponara, R., and Tramutoli, V.: Evaluation of a new satellite-based method for forest fire detection, Int. J. Remote Sens., 22(9), 1799-1826, 2001.

Cuomo, V., Filizzola, C., Pergola, N., Pietrapertosa, C., and Tramutoli, V.: A self-sufficient approach for GERB cloudy radiance detection, Atmos. Res., 72(1-4), 39-56, 2004.

Di Bello, G., Filizzola, C., Lacava, T., Marchese, F., Pergola, N., Pietrapertosa, C., Piscitelli, S., Scaffidi, I., and Tramutoli, V.: Robust Satellite Techniques for Volcanic and Seismic Hazards Monitoring, Ann. Geophys-Italy, 47(1), 49-64, 2004.

Filizzola, C., Pergola, N., Pietrapertosa, C., and Tramutoli, V.: Robust satellite techniques for seismically active areas monitoring: a sensitivity analysis on September 7, 1999 Athens's earthquake, Phys. Chem. Earth, 29, 517-527, 2004.

Filizzola, C., Lacava, T., Marchese, F., Pergola, N., Scaffidi, I., and Tramutoli, V.: Assessing RAT (Robust AVHRR Techniques) performances for volcanic ash cloud detection and monitoring in near realtime: The 2002 eruption of Mt. Etna (Italy), Remote Sens. Environ., 107, 440-454, 2007.

Genzano, N., Aliano, C., Filizzola, C., Pergola, N., and Tramutoli, V.: A robust satellite technique for monitoring seismically active areas: The case of Bhuj-Gujarat earthquake, Tectonophysics, 431, 197-210, 2007.

Genzano, N., Aliano, C., Corrado, R., Filizzola, C., Lisi, M., Paciello, R., Pergola, N., Tsamalashvili, T., and Tramutoli, V.: Assessing of the Robust Satellite Techniques (RST) in areas with moderate seismicity, in: Multitemp 2009, Fifth International Workshop on the Analysis of Multitemporal Remote Sensing Images, Mistic, Connecticut, USA, 307-314, 28-30 July 2009.

Gorny, V. I., Salman, A. G., Tronin, A. A., and Shilin, B. B.: The Earth outgoing IR radiation as an indicator of seismic activity, in: Proceeding of the Academy of Sciences of the USSR, 301, 67-69, 1988.

Hamza, V. M.: Tectonic leakage of fault bounded aquifers subject to non-isothermal recharge: A mechanism generating thermal precursors to seismic events, Phys. Earth Planet. In., 126, 163-177, 2001.

INGV (Istituto Nazionale di Geofisica e Vulcanologia): The Italian seismic bullettin, available at: http://iside.rm.ingv.it/iside/ standard/index.jsp, 2009.

Lacava, T., Cuomo, V., Di Leo, E. V., Pergola, N., Romano, F., and Tramutoli, V.: Improving soil wetness variations monitoring from passive microwave satellite data: the case of April 2000 Hungary flood, Remote Sens. Environ., 96/2, 135-148, 2005.

Lacava, T., Di Leo, E. V., Pergola, N., and Tramutoli, V.: Spacetime soil wetness variations monitoring by a multi-temporal microwave satellite records analysis, Phys. Chem. Earth, 31, 1274 1283, 2006.

Lacava, T., Filizzola, C., Pergola, N., Sannazzaro, F., and Tramutoli, V.: Improving flood monitoring by RAT (Robust AVHRR Technique) approach: the case of April 2000 Hungary flood, Int. J. Remote Sens., in press, 2009.

Mareev, E. A., Iudin, D. I., and Molchanov, O. A.: Mosaic source of internal gravity waves associated with seismic activity, in: Seismo-Electromagnetics (Lithosphere-Atmosphere-Ionosphere Coupling), edited by: Hayakawa, M. and Molchanov, O., TERRUPUB, 335-342, 2002.

Molchanov, O. A.: On the origin of low- and middle-latitude ionospheric turbulence, Phys. Chem. Earth, 29, 559-567, 2004.

Molchanov, O. and Hayakawa, M.: Seismo-electromagnetics and related phenomena: History and latest results, TERRAPUB, Tokyo, 190 pp., 2008.

Molchanov, O., Fedorov, E., Schekotov, A., Gordeev, E., Chebrov, V., Surkov, V., Rozhnoi, A., Andreevsky, S., Iudin, D., Yunga, S., Lutikov, A., Hayakawa, M., and Biagi, P. F.: Lithosphereatmosphere-ionosphere coupling as governing mechanism for preseismic short-term events in atmosphere and ionosphere, Nat. Hazards Earth Syst. Sci., 4, 757-767, 2004,

http://www.nat-hazards-earth-syst-sci.net/4/757/2004/.

Marchese, F., Pergola, N., and Telesca, L.: Investigating the temporal fluctuations in satellite Advanced very High Resolution Radiometer thermal signals measured in the volcanic area of Etna (Italy), Fluct. Noise Lett., 6(3), 305-316, 2006.

Mazzeo, G., Marchese, F., Filizzola, C., Pergola, N., and Tramutoli, V.: A Multi-temporal Robust Satellite Technique (RST) for forest fire detection, in: Multitemp 2007, Louven, Belgium, 1-6, doi:10.1109/MULTITEMP.2007.4293060, available at: http://ieeexplore.ieee.org/xpl/tocresult.jsp?isnumber= 4293029\&isYear=2007, 18-20 July 2007.

Ouzounov, D. and Freund, D.: Mid-infrared emission prior to strong earthquakes analyzed by remote sensing data, Adv. Space Res., 33, 268-273, 2004.

Pergola, N., Pietrapertosa, C., Lacava, T., and Tramutoli, V.: Robust satellite techniques for monitoring volcanic eruptions, Ann. Geofis, 44(2), 167-177, 2001.

Pergola, N., Tramutoli, V., and Marchese, F.: Automated detection of thermal features of active volcanoes by means of infrared AVHRR records, Remote Sens. Environ., 93, 311-327, 2004a.

Pergola, N., Tramutoli, V., Scaffidi, I., Lacava, T., and Marchese, F.: Improving volcanic ash clouds detection by a robust satellite 
technique, Remote Sens. Environ., 90(1), 1-22, 2004b.

Pulinets, S. A., Boyarchuk, K. A., Hegai, V. V., and Karelin, A. V.: Conception and model of seismo-ionosphere-magnetosphere coupling, in: Seismo-Electromagnetics:

Lithosphere-Atmosphere-Ionosphere Coupling, edited by: Hayakawa, M. and Molchanov, O. A., Terra Scientific Publishing Co., Tokyo, 353-361, 2002.

Pulinets, S. A., Ouzounov, D., Karelin, A. V., Boyarchuk, K. A., and Pokhmelnykh, L. A.: The physical nature of thermal anomalies observed before strong earthquakes, Phys. Chem. Earth, 31, 143153, 2006.

Pulinets, S. A., Biagi, P., Tramutoli, V., Legen'ka, A. D., and Depuev, V. K.: Irpinia earthquake 23 November 1980 - Lesson from Nature revealed by joint data analysis, Ann. Geophys., 50(1), 61-78, 2007.

Qiang, Z. J., Xu, X. D., and Dian, C. G.: Thermal infrared anomaly precursor of impending earthquakes, Chinese Sci. Bull., 36(4), 319-323, 1991.

Qiang, Z. J. and Dian, C. G.: Satellite thermal infrared impending temperature increase precursor of Gonghe earthquake of magnitude 7.0, Qinghai Province, Geoscience, 6(3), 297-300, 1992.

Qiang, Z. J., Xu, X. D., and Dian, C. G.: Thermal infrared anomaly precursor of impending earthquakes, Pure Appl. Geophys., 149, 159-171, 1997.

Surkov, V. V., Pokhotelov, O. A., Parrot, M., and Hayakawa, M.: On the origin of stable IR anomalies detected by satellites above seismo-active regions, Phys. Chem. Earth, 31, 164-171, 2006.

Tramutoli, V.:

Robust AVHRR techniques (RAT) for environmental monitoring: theory and applications, in: Earth surface remote sensing II, SPIE proceedings series, 3496, 101-113, 1998.

Tramutoli, V., Claps, P., Marella, M., Pergola, N., Pietrapertosa, C., and Sileo, C.: Hydrological implications of remotely-sensed thermal inertia, in: Remote Sensing and Hydrology 2000, edited by: Owe, M., Brubaker, K., Ritchie, J., and Rango, A., IAHS Publ., 267, 207-211, 2001a.

Tramutoli, V., Di Bello, G., Pergola, N., and Piscitelli, S.: Robust satellite techniques for remote sensing of seismically active areas, Ann. Geophys., 44(2), 295-312, 2001b.

Tramutoli, V., Pergola, N., and Pietrapertosa, C.: Training on NOAAAVHRR of robust satellite techniques for next generation of weather satellites: an application to the study of spacetime evolution of Pinatubo's stratospheric volcanic cloud over Europe, in: IRS 2000: Current Problems in Atmospheric Radiation, edited by: Smith, W. L. and Timofeyev, Yu. M., Deepak Publishing, Hampton, 36-39, 2001c.
Tramutoli, V., Cuomo, V., Filizzola, C., Pergola, N., and Pietrapertosa, C.: Assessing the potential of thermal infrared satellite surveys for monitoring seismically active areas: The case of Kocaeli (Ýzmit) earthquake, August 17, 1999, Remote Sens. Environ., 96, 409-426, 2005.

Tramutoli, V: Robust Satellite Techniques (RST) for natural and environmental hazards monitoring and mitigation: ten years of successful applications, in: The 9th International Symposium on Physical Measurements and Signatures in Remote Sensing, Beijing (China), edited by: Liang, S., Liu, J., Li, X., Liu, R., and Schaepman, M., ISPRS, vol. XXXVI (7/W20), 792-795, ISSN 1682-1750, 2005.

Tramutoli, V.: Robust Satellite Techniques (RST) for Natural and Environmental Hazards Monitoring and Mitigation: Theory and Applications, in: Proceedings of Multitemp 2007, 1-6, doi:10.1109/MULTITEMP.2007.4293057, available at: http://ieeexplore.ieee.org/xpl/tocresult.jsp?isnumber= 4293029\&is Year=2007, 2007.

Tramutoli, V., Aliano, C., Corrado, R., Filizzola, C., Genzano, N., Lisi, M., Lanorte, V., Tsamalashvili, T., and Pergola, N.: Abrupt change in greenhouse gases emission rate as a possible genetic model of TIR anomalies observed from satellite in Earthquake active regions, in: Proceedings of 33rd International Symposium on Remote Sensing of Environment (ISRSE33), Stresa, Lago Maggiore, Italy, 4-8 May 2009.

Tronin, A. A.: Satellite thermal survey - a new tool for the study of seismoactive regions, Int. J. Remote Sens., 41(8), 1439-1455, 1996.

Tronin, A. A.: Thermal IR satellite sensor data application for earthquake research in China, Int. J. Remote Sens., 21(16), 3169 3177, 2000.

Tronin, A. A., Hayakawa, M., and Molchanov, O. A.: Thermal IR satellite data application for earthquake research in Japan and China, J. Geodyn., 33(4-5), 519-534, 2002.

Tronin, A. A., Biagi, P. F., Molchanov, O. A., Khatkevich, Y. M., and Gordeev, E. I.: Temperature variations related to earthquakes from simultaneous observation at the ground stations and by satellites, Phys. Chem. Earth, 29, 501-506, 2004. 